\title{
AS CONSEQUENNCIAS DE UMA DIETA VEGETARIANA/VEGANA DURANTE A GESTAÇÃO: UMA REVISÃO
}

\author{
CATEGORIA: CLÍNICO. \\ CENTRO UNIVERSITÁRIO SÃO CAMILO
}

$\underline{\text { Giannetto, B }}^{1}$ - Endereço Av. Hilário Pereira de Souza, número 492 -

Telefone: (11) 98224-1038 - Email: beagiannetto@gmail.com

\author{
RODRIGUES, $\mathbf{G}^{1}$ \\ KOIKE, D'; \\ VELLENICH, GAH ${ }^{1}$ \\ PEREIRA, M M $\mathbf{M}^{2}$
}

1. Discente do Centro Universitário São Camilo

2. Docente do Centro Universitário São Camilo 


\section{AS CONSEQUÊNCIAS DE UMA DIETA VEGETARIANA/VEGANA DURANTE A GESTAÇÃO: UMA REVISÃO}

CATEGORIA: CLÍNICO.

DESCRITORES: Nutrients, Micronutrients, Vegetarian pregnancy 


\section{RESUMO}

INTRODUÇÃO: Os adeptos das dietas vegetarianas e veganas têm aumentado em todo o mundo nas últimas décadas. E, devido aos riscos de deficiências nutricionais, as gestantes merecem um cuidado especial, afinal, a falta de vitaminas, como A, B12, Ca, Zn e ácido fólico, podem afetar esta paciente e seu concepto.

METODOLOGIA: Foi realizada uma revisão sistemática da literatura na base de dados PubMed utilizando os termos; "((Nutrients) AND Micronutrients) AND Vegetarian pregnancy"; no período de 2010 a 2019. Um total de 19 artigos foram encontrados. Após aplicação dos critérios de exclusão: artigos de revisão e relatos de caso; foram utilizados 6 estudos originais.

OBJETIVOS: Essa revisão foi realizada no intuito de verificar os possíveis efeitos de uma dieta vegetariana durante a gestação.

RESULTADOS: Dois estudos demonstraram que é comum o baixo nível de B12 em gestantes e quando levamos em consideração as que se utilizam de dietas veganas é mais evidente esse déficit, em um deles, calculou-se uma deficiência de até $40 \%$ dessa vitamina na mãe e $29 \%$ no neonato. Já em outro que analisou o consumo em as gestantes de Shaanxi (China), constatou a baixa ingestão de vitamina $\mathrm{A}, \mathrm{Ca}, \mathrm{Zn}$ e ácido fólico quando comparadas a outros grupos de grávidas, além de que as que tinham o padrão dietético vegetariano ou petiscos tinham dietas menos balanceadas e ingeriam menos nutrientes; já que as carnes contribuem com $67,1 \%$ de vitamina A em comparação com os vegetais, apenas 19,6\%. Outro estudo demonstrou que consumidores de alimentos orgânicos aderem mais frequentemente ao vegetarianismo ou antroposofia do que os que consomem apenas alimentos convencionais; ainda com relação ao consumo de alimentos orgânicos, verificou-se um menor consumo de vitamina D e B12. Ademais, deve-se dar destaque à vitamina B12, visto que 3 estudos a evidenciam durante a gravidez; a importância da mesma é notada à medida que em baixos níveis podem causar falha na maturação de hemácias, desmielinização de fibras nervosas da medula espinal, anemia perniciosa e má formação neurológica do feto.

CONCLUSÃO: Pode-se concluir que a avaliação da dieta e nutrição das gestantes, sobretudo nas que adotam é de suma importância e deve ser acompanhada por uma equipe multidisciplinar. Assim, prejuízos nutricionais às grávidas e aos bebês serão evitados, bem como problemas mais graves. 


\begin{abstract}
INTRODUCTION: Supporters of the vegan and vegetarian diet style have grown in number in the last few decades. And, because of nutritional deficiencies, pregnant women should receive extra care, after all, the lack of vitamins, such as A, B12, Ca, Zn and folic acid can affect the patient and her fetus.

METHODS: A systematic review of the literature was done on the database PubMed, using the terms "((Nutrients) AND Micronutrients) AND Vegetarian pregnancy"; on the period of 2010 to 2019. A total of 19 articles were found. After the exclusion criteria was applied (reviews and case reports were excluded), 6 original studies were analyzed.

OBJECTIVES: This review was done in order to investigate the possible effects of a vegetarian diet during gestation.

RESULTS: Two studies showed that low B12 status was common in pregnant women, and this deficit is even more evident in women following vegan diets. One of them calculated this deficiency to be up to $40 \%$ in the mother and $29 \%$ in the newborn. Another study evaluated the consumption in pregnant women from Shaanxi (China), and found low ingestion of vitamin A, $\mathrm{Ca}, \mathrm{Zn}$ and folic acid when compared with other groups of pregnant women. Furthermore, those who had their diet style based on snacks or vegetarian had less balanced diets and ingested less nutrients, because meat contributed $67,1 \%$ more with vitamin A when compared to vegetables, who contributed only $19,6 \%$. Another study showed that organic food consumers adhered more frequently to vegetarianism or anthroposophy when compared to those who consumed only conventional foods. Still in relation to the organic foods, it was discovered less consumption of vitamin B12 and D. In addition, there should be more attention to vitamin b12 since 3 studies evidence its importance during pregnancy. Low quantities of this vitamin is associated with failure in the maturation of red blood cells, demyelination of nerve fibers in the spinal cord, pernicious anemia and neurologic malformations in the fetus.

CONCLUSION: It can be inferred that the evaluation of the diet and nutrition of pregnant women, even more importantly of those following the vegan and vegetarian diet pattern, should be made and accompanied by a multidisciplinary team. Thereby, nutritional risks and losses to the pregnant women and baby can be avoided, as well as more serious problems.
\end{abstract}




\section{INTRODUÇÃO}

Os adeptos das dietas vegetarianas e veganas têm aumentado em todo o mundo nas últimas décadas, dentre esses adeptos devem ser incluídas as gestantes. A maior adoção dessa dieta ocorre não só por questões nutricionais, mas também pelo estilo de vida e questões éticas de alguns indivíduos [1].

Segundo a Sociedade Vegetariana Brasileira, os vegetarianos são considerados aqueles que excluem de sua alimentação todos os tipos de carne, aves e peixes e seus derivados, podendo ou não utilizar laticínios ou ovos. O vegetarianismo inclui o veganismo, que é a prática de não utilizar produtos oriundos do reino animal para nenhum fim (alimentar, higiênico, de vestuário etc.). O indivíduo que segue a dieta vegetariana pode ser classificado de acordo com o consumo de subprodutos animais (ovos e laticínios): ovolactovegetariano é o vegetariano que utiliza ovos, leite e laticínios na alimentação; lactovegetariano é o vegetariano que não utiliza ovos, mas faz uso de leite e laticínios; ovovegetariano é o vegetariano que não utiliza laticínios mas consome ovos; vegetariano estrito ou vegetariano puro é aquele que não utiliza nenhum derivado animal na sua alimentação; vegano é o indivíduo vegetariano estrito que recusa o uso de componentes animais não alimentícios, como vestimentas de couro, lã e seda, assim como produtos testados em animais [2]. Nota-se que a restrição à carne tem diversas vertentes e as consequências que pode causar também são variadas [3].

Atualmente, existem muitas controvérsias no que diz respeito aos reais benefícios das dietas vegetariana e vegana. Contudo, já é sabido que essas dietas implicam em deficiências de vitaminas A (retinol), B12 (cianocobalamina), D, cálcio (Ca), zinco (Zn) e ácido fólico, se não acompanhadas corretamente [3].

As gestantes merecem um cuidado especial, devido ao risco de deficiência nutricional fisiológico, que se dá pelo crescimento do feto, afinal, a falta de vitaminas, como A, B12, D, cálcio, zinco e ácido fólico, podem afetar esta paciente e seu concepto. O recém-nascido pode ser afetado por esse déficit e ter diversos prejuízos, sobretudo metabólicos [4].

\section{OBJETIVO}

Essa revisão foi realizada no intuito de verificar os possíveis efeitos que uma dieta vegetariana ou vegana durante a gestação podem gerar à gestante e ao concepto.

\section{METODOLOGIA}

Foi realizada uma revisão sistemática da literatura na base de dados PubMed utilizando os termos; “((Nutrients) AND Micronutrients) AND Vegetarian pregnancy"; no período de 2010 a 2019. Um total de 19 artigos foram encontrados. Foram incluídos estudos que respondiam à questão norteadora dessa revisão e após aplicação dos critérios de exclusão: artigos de revisão e relatos de caso; foram utilizados 6 estudos originais.

\section{RESULTADOS:}

Os resultados encontrados através dessa revisão sistemática de literatura encontram-se na tabela abaixo: 


\begin{tabular}{|c|c|c|c|c|c|}
\hline $\begin{array}{l}\text { Título do } \\
\text { Artigo }\end{array}$ & Ano & $\begin{array}{l}\text { Tipo de } \\
\text { Artigo }\end{array}$ & Amostra & Resultado & Conclusão \\
\hline $\begin{array}{l}\text { Suboptimal } \\
\text { Iodine Status } \\
\text { and Low } \\
\text { Iodine } \\
\text { Knowledge } \\
\text { in Young } \\
\text { Norwegian } \\
\text { Women }\end{array}$ & 2018 & $\begin{array}{l}\text { Estudo de } \\
\text { coorte }\end{array}$ & $\begin{array}{l}403 \\
\text { mulheres } \\
\text { não } \\
\text { grávidas } \\
\text { com } \\
\text { idade } \\
\text { entre } 18 \text { e } \\
30 \text { anos }\end{array}$ & $\begin{array}{l}\text { Norueguesas não } \\
\text { gestantes têm } \\
\text { deficiência nos } \\
\text { níveis de iodo, } \\
\text { sobretudo as que } \\
\text { adotam uma dieta } \\
\text { vegetariana ou } \\
\text { vegana. Além } \\
\text { disso, não há um } \\
\text { conhecimento } \\
\text { difundido sobre as } \\
\text { principais fontes } \\
\text { de iodo. }\end{array}$ & $\begin{array}{l}\text { As mulheres } \\
\text { jovens na Noruega } \\
\text { são deficientes de } \\
\text { leve a } \\
\text { moderadamente } \\
\text { com iodo, e } \\
\text { estratégias de } \\
\text { saúde pública são } \\
\text { necessárias para } \\
\text { melhorar e } \\
\text { garantir o status } \\
\text { adequado de iodo. }\end{array}$ \\
\hline
\end{tabular}




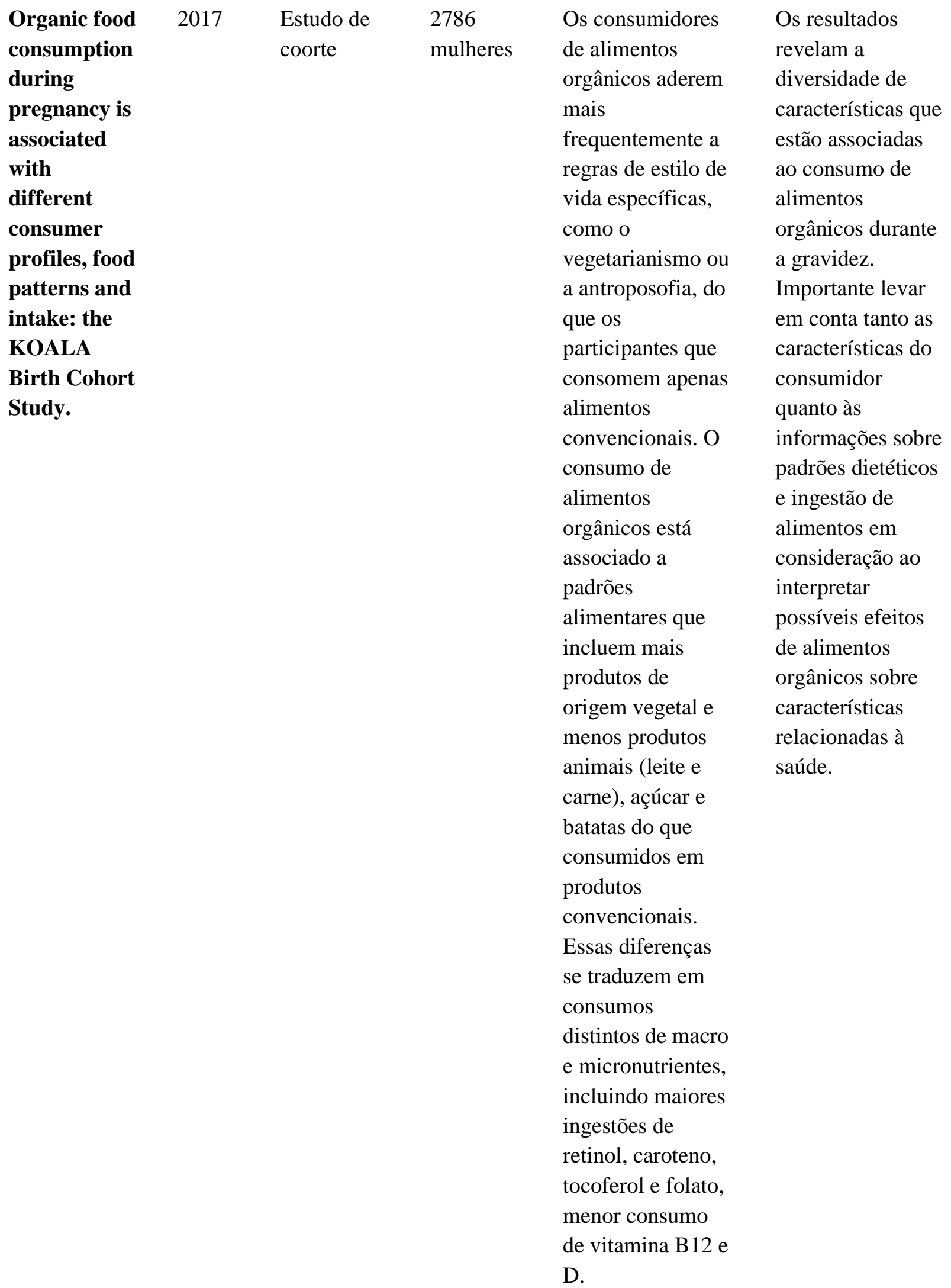




\begin{tabular}{|c|c|c|c|c|c|}
\hline $\begin{array}{l}\text { Dietary } \\
\text { intake and } \\
\text { dietary } \\
\text { patterns } \\
\text { among } \\
\text { pregnant } \\
\text { women in } \\
\text { Northwest } \\
\text { China }\end{array}$ & 2016 & $\begin{array}{l}\text { Inquérito } \\
\text { de base } \\
\text { populacio- } \\
\text { nal }\end{array}$ & $\begin{array}{l}7462 \\
\text { grávidas } \\
\text { no } \\
\text { período } \\
\text { de } 2012 \text { a } \\
2013\end{array}$ & $\begin{array}{l}\text { Foram } \\
\text { encontrados três } \\
\text { padrões dietéticos: } \\
\text { balanceado, } \\
\text { vegetariano e de } \\
\text { petiscos, sendo } \\
\text { que mulheres nas } \\
\text { mulheres desses } \\
\text { últimos dois } \\
\text { grupos têm dieta } \\
\text { menos balanceada } \\
\text { e ingerem menos } \\
\text { nutrientes. Essas } \\
\text { mulheres têm } \\
\text { maior ingestão de } \\
\text { gorduras, niacina e } \\
\text { vitamina E e } \\
\text { menor ingestão de } \\
\text { vitamina A, Ca, } \\
\text { Zn e ácido fólico } \\
\text { quando } \\
\text { comparadas a } \\
\text { outros grupos de } \\
\text { grávidas. }\end{array}$ & $\begin{array}{l}\text { As mulheres de } \\
\text { Shaanxi tem } \\
\text { pouca ingestão de } \\
\text { vitamina A, Ca e } \\
\text { ácido fólico, } \\
\text { sendo necessária a } \\
\text { implantação de } \\
\text { programas para } \\
\text { melhorar a dieta } \\
\text { dessa população, } \\
\text { sobretudo de } \\
\text { gestantes } \\
\text { sociodemografica } \\
\text { mente } \\
\text { desfavorecidas. }\end{array}$ \\
\hline
\end{tabular}




\begin{tabular}{|c|c|c|c|c|c|}
\hline $\begin{array}{l}\text { Low serum } \\
\text { vitamin B12 } \\
\text { concentrati- } \\
\text { ons are } \\
\text { prevalent in } \\
\text { a cohort of } \\
\text { pregnant } \\
\text { canadian } \\
\text { women }\end{array}$ & 2016 & $\begin{array}{l}\text { Estudo de } \\
\text { coorte }\end{array}$ & $\begin{array}{l}368 \\
\text { mulheres } \\
\text { grávidas }\end{array}$ & $\begin{array}{l}\text { Apesar de } 90 \% \text { da } \\
\text { amostra estar } \\
\text { tomando } \\
\text { suplemento de } \\
\text { B12 ou ter na } \\
\text { dieta uma } \\
\text { quantidade acima } \\
\text { do esperado, 16,95 } \\
\text { da amostra tinha } \\
\text { deficiência de B12 } \\
\text { no início da } \\
\text { gestação. O } \\
\text { sangue do cordão } \\
\text { umbilical continha } \\
\text { quantidades mais } \\
\text { elevadas de B12, } \\
\text { sendo relacionado } \\
\text { com a necessidade } \\
\text { maior do feto por } \\
\text { essa vitamina. } \\
\text { Outrossim, } \\
\text { demonstrou-se que } \\
\text { mulheres } \\
\text { consumindo } \\
\text { suplementos de } \\
\text { B12 durante a } \\
\text { gestação tiveram } \\
\text { aumento no nível } \\
\text { dessa vitamina no } \\
\text { sangue materno e } \\
\text { do cordão } \\
\text { umbilical. }\end{array}$ & $\begin{array}{l}\text { A prevalência de } \\
\text { deficiência de B12 } \\
\text { foi observada } \\
\text { nessa coorte de } \\
\text { mulheres grávidas } \\
\text { no Canadá, e } \\
\text { como o interesse } \\
\text { em dietas veganas } \\
\text { (em que a } \\
\text { ingestão de B12 é } \\
\text { menor) tem } \\
\text { aumentado, assim } \\
\text { são necessárias } \\
\text { maiores } \\
\text { informações sobre } \\
\text { a alimentação das } \\
\text { gestantes nesse } \\
\text { estudo. }\end{array}$ \\
\hline
\end{tabular}




\begin{tabular}{|c|c|c|c|c|c|}
\hline $\begin{array}{l}\text { Low } \\
\text { maternal } \\
\text { vitamin B12 } \\
\text { status is } \\
\text { associated } \\
\text { with lower } \\
\text { cord blood } \\
\text { HDL } \\
\text { cholesterol } \\
\text { in white } \\
\text { Caucasians } \\
\text { living in the } \\
\text { UK. }\end{array}$ & 2015 & $\begin{array}{l}\text { Estudo } \\
\text { Transversal }\end{array}$ & $\begin{array}{l}91 \text { pares } \\
\text { mãe-filho } \\
(n=182)\end{array}$ & $\begin{array}{l}\text { A prevalência de } \\
\text { níveis séricos } \\
\text { baixos de vitamina } \\
\text { B12 e folato nas } \\
\text { mulheres durante } \\
\text { a gravidez foi de } \\
40 \% \text { e } 11 \% \text { nas } \\
\text { mães e } 29 \% \text { nos } \\
\text { neonatos, } \\
\text { respectivamente. } \\
\text { As crianças } \\
\text { nascidas de mães } \\
\text { com baixo status } \\
\text { de B12 } \\
\text { apresentaram } \\
\text { níveis } \\
\text { significativamente } \\
\text { mais baixos de } \\
\text { B12 em } \\
\text { comparação com } \\
\text { aquelas nascidas } \\
\text { de mães com } \\
\text { níveis normais. }\end{array}$ & $\begin{array}{l}\text { O baixo nível de } \\
\text { vitamina B12 é } \\
\text { comum em } \\
\text { mulheres brancas } \\
\text { e está } \\
\text { independentement } \\
\text { e associado ao } \\
\text { colesterol } \\
\text { sanguíneo adverso } \\
\text { do cordão. Além } \\
\text { disso, a vitamina } \\
\text { B12 materna } \\
\text { desempenha um } \\
\text { papel importante } \\
\text { no metabolismo } \\
\text { lipídico da prole e } \\
\text { que sua restrição } \\
\text { no útero pode } \\
\text { predispô-la ao } \\
\text { aumento do risco } \\
\text { metabólico, } \\
\text { inclusive pode } \\
\text { gerar resistência à } \\
\text { insulina no feto. }\end{array}$ \\
\hline
\end{tabular}




\begin{tabular}{|c|c|c|c|c|c|}
\hline $\begin{array}{l}\text { Nutritional } \\
\text { factors and } \\
\text { hypospadias } \\
\text { risk }\end{array}$ & 2012 & $\begin{array}{l}\text { Caso } \\
\text { controle }\end{array}$ & $\begin{array}{l}4.368 \\
(3.118 \\
\text { grupo } \\
\text { controle) }\end{array}$ & $\begin{array}{l}\text { A ingestão de } \\
\text { produtos animais } \\
\text { não foi associada a } \\
\text { hipospádia. A } \\
\text { frequência de } \\
\text { consumo de carne } \\
\text { ou outros produtos } \\
\text { animais também } \\
\text { não foi associada } \\
\text { com hipospádia, } \\
\text { nem foi ingestão } \\
\text { de ferro ou vários } \\
\text { nutrientes que } \\
\text { estão } \\
\text { potencialmente } \\
\text { relacionados ao } \\
\text { metabolismo de } \\
\text { estrogênio. A } \\
\text { qualidade da dieta } \\
\text { também não foi } \\
\text { associada à } \\
\text { hipospádia. }\end{array}$ & $\begin{array}{l}\text { Este grande } \\
\text { estudo não suporta } \\
\text { uma associação de } \\
\text { dieta vegetariana } \\
\text { ou pior qualidade } \\
\text { da dieta com } \\
\text { hipospádia. }\end{array}$ \\
\hline
\end{tabular}

\section{DISCUSSÃO:}

A falta de vitamina A, segundo a Sociedade Brasileira de Pediatria, influencia o metabolismo do ferro com a diminuição desse nas hemácias, o que dificulta a diferenciação das hemácias e reduz a mobilização do depósito de hemácias no fígado [5].

A vitamina B12, que naturalmente encontra-se em baixos níveis durante a gestação, é adquirida pela digestão de proteínas de origem animal, principalmente bife de fígado, mariscos e ostras, segundo a Associação Brasileira de Nutrologia. Sua deficiência pode levar a transtornos hematológicos, neurológicos e cardiovasculares por meio de acidose metabólica [6]. A deficiência desta também pode estar associada ao baixo peso ao nascer, problemas metabólicos e cognitivos no concepto. [6]

A vitamina D - essencial ao metabolismo ósseo - quando em baixos níveis, implica em raquitismo e retardo de crescimento (em crianças) e osteomalácia e hiperparatireoidismo secundário favorecendo a perda óssea em adultos. Além disso, é descrito que a essa vitamina está associada a outros contextos clínicos, como diabetes, doenças cardiovasculares, distúrbios psiquiátricos e doenças neuro-musculares [7]. As principais fontes alimentícias dessa vitamina são óleo de fígado de bacalhau, óleo de salmão e ostras cruas, ambas de origem animal, contrapondo-se as dietas vegetariana e vegana [8].

A hipocalcemia, sobretudo em crianças, pode levar a tetania e até mesmo convulsões generalizadas; deve-se ressaltar que nas grávidas e lactentes os níveis de cálcio estão fisiologicamente diminuídos [9]. Soma-se a isso, a ingestão de Ca que está associada ao risco reduzido de pré-eclâmpsia e parto prematuro [10]. A principal fonte alimentar de cálcio para a maior parte da população é o leite e seus derivados (queijos e iogurtes). As verduras verde-escuras 
como brócolis e couve são fontes alternativas para obter cálcio em dietas veganas, por exemplo, porém a biodisponibilidade diminui aproximadamente 100 microgramas ao comparar 190 grama de espinafre cozido com 240 grama de leite desnatado. Além de dietas com restrições, outros fatores que influenciam no consumo de alimentos ricos em cálcio é o crescente número de refeições realizadas em restaurantes, o aumento do consumo de refrigerantes (substituindo o leite) e a omissão de refeições como o café da manhã [11].

A deficiência de zinco tem inúmeras consequências, como hipogonadismo, danos oxidativos, alterações do sistema imune, danos psicológicos [12]. Uma dieta pobre em zinco também pode estar relacionada a consequências adversas a longo prazo no crescimento,

imunidade e status metabólico da prole sobrevivente [10]. Marisco, ostras, carnes vermelhas, fígado, miúdos e ovos são consideradas as maiores fontes de zinco [12].

Baixos níveis de ácido fólico na gestação são gravíssimos, uma vez que estão associados a defeitos no tubo neural no feto e anemia megaloblástica na mãe. As principais fontes de folato nos alimentos são fígado de galinha, fígado de peru e levedo de cerveja, segundo a Associação Brasileira de Nutrologia.

Ao encontro dessas informações, dois estudos demonstraram que é comum o baixo nível de B12 em gestantes e quando leva-se em consideração as que se utilizam de dietas vegetarianas ou veganas é mais evidente esse déficit.

Em um deles, calculou-se uma deficiência de até 40\% dessa vitamina na mãe e $29 \%$ no neonato, além disso, as crianças nascidas de mães com baixos níveis de B12 apresentaram níveis de cianocobalamina significativamente mais baixos ao nascer, sobretudo quando gestantes eram tabagistas ou se eram multíparas. Nota-se que os nascidos dessas mães com baixo nível desta vitamina apresentaram níveis séricos de HDL menores e níveis de triglicerídeos e homocisteína mais altos em relação a mães sem a deficiência. Assim, os níveis maternos de vitamina B12 estão adversamente associados a marcadores de risco metabólico ao nascer, particularmente em relação ao perfil lipídico [4].

À luz da bioquímica, a vitamina B12 atua como co-fator na conversão de homocisteína em metionina e na conversão de metilmalonil Co-A (MM-CoA) em succinil Co-A. Assim, é necessária para metilação de DNA, proteína e lipídeos; e com a sua diminuição, há a inibição da carnitina palmitoil transferase - 1, podendo levar a um maior risco metabólico na prole por programação epigenética adversa, além de afetar diretamente a $\beta$-oxidação de ácidos graxos. Portanto, baixos níveis maternos de vitamina B12 foram associados à resistência à insulina dos filhos, perfil lipídico adverso (colesterol total e triglicerídeos mais altos); os adipócitos cultivados em baixa condição de B12 apresentaram níveis aumentados de colesterol e o IMC dos conceptos foi maior no grupo com baixo índice de vitamina B12 [4].

Já em outro estudo, mesmo que $90 \%$ da amostra já tomasse suplementos da vitamina B12 ou possuísse níveis adequados na dieta, $16,95 \%$ da amostra tinha deficiência da vitamina no início da gestação, uma vez que o feto necessita de altas quantidades de B12, demonstrado pelos altos níveis da vitamina no cordão umbilical. Para mais, a suplementação durante a gestação promoveu aumento dos níveis séricos da mãe e do cordão e não houve associação entre a concentração de B12 e o genoma fetal. Somado a isso, a deficiência materna dessa vitamina está associada a baixos pesos do recém-nascido, resistência à insulina e comprometimento do desenvolvimento cognitivo da prole. [13]

Outro estudo que analisou a dieta de 7.462 gestantes foram encontrados três padrões de dieta: uma balanceada, a vegetariana e a de petiscos. O consumo em as gestantes de Shaanxi (China), constatou que aquelas que aderiram o padrão dietético vegetariano e de petiscos possuíam baixa ingestão de nutrientes e vitaminas como A, Ca, Zn e ácido fólico e tinham dietas menos balanceadas quando comparadas a outros grupos de grávidas. Essa baixa ingestão se dá porque as carnes contribuem com $67,1 \%$ de vitamina A em comparação com os vegetais, que 
contribuem com apenas 19,6\%. Ademais, os alimentos vegetais incluindo grãos de cereais, nozes e legumes que foram consumidos com relativa frequência na população analisada contêm altos níveis de fitato, um inibidor de Ca e Zn absorção. Assim, a biodisponibilidade de $\mathrm{Ca}$ e $\mathrm{Zn}$ pode ser prejudicada entre a população, bem como o Ferro, que foi ingerido apenas de fontes vegetais. Também é possível observar que as participantes com alta adesão ao padrão equilibrado eram mais instruídas, o que indica certa necessidade de programas que instruam as gestantes sobre os padrões alimentares, principalmente naquelas sociodemograficamente desfavorecidas [10].

Outro artigo, por sua vez, sustentava a hipótese de que a hipospádia no bebê estava associada a uma dieta vegetariana ou vegana. Contudo os resultados do estudo não a sustentaram. A frequência de consumo de carne ou outros produtos animais também não foi associada com hipospádia, nem foi ingestão de ferro ou outros nutrientes que estão potencialmente relacionados ao metabolismo de estrogênio. A qualidade da dieta também não foi associada à hipospádia [14].

Foi analisado por um artigo níveis de iodo e constatou-se que as mulheres com dieta não vegetariana ou vegana tinham maiores quantidades desse elemento no organismo quando comparados com aquelas que adotavam uma dieta vegetariana ou vegana. Notou-se que a população em questão não possuía conhecimento sobre as fontes de iodo e sobre a importância deste. O estudo foi realizado em mulheres não gestante, pois seus futuros filhos podem ser suscetíveis aos efeitos adversos da deficiência de iodo. Causa preocupação a baixa ingestão e concentração de iodo no organismo das gestantes, visto que o iodo contribui para o desenvolvimento fetal. Por isso, estratégias de saúde pública são necessárias para melhorar e garantir a ingestão adequada de iodo nesse grupo vulnerável [15].

Outro estudo demonstrou que consumidores de alimentos orgânicos aderem mais frequentemente ao vegetarianismo ou antroposofia do que os que consomem apenas alimentos convencionais; ainda com relação ao consumo de alimentos orgânicos, verificou-se um menor consumo de vitamina D e B12, que são provenientes de alimentos de origem animal. Contudo, os consumidores de produtos orgânicos apresentaram maior consumo de fibras e de vitaminas como retinol, caroteno, tocoferol e folato [16].

Ademais, deve-se dar destaque à vitamina B12, visto que 3 estudos a evidenciam durante a gravidez; a importância da mesma é notada à medida que em baixos níveis podem causar falha na maturação de hemácias, desmielinização de fibras nervosas da medula espinal, anemia perniciosa e má formação neurológica do feto.

\section{CONCLUSÃO:}

Pode-se concluir que a avaliação da dieta e nutrição das gestantes, sobretudo nas que adotam uma dieta vegetariana ou vegana é de suma importância e deve ser acompanhada por uma equipe multidisciplinar no período pré e pós-natal, e se necessário a gestante deve suplementar a deficiência dos nutrientes. Assim, prejuízos nutricionais às grávidas e aos bebês podem ser evitados, bem como problemas mais graves. Nota-se que a autonomia da paciente sempre deve ser respeitada e que o profissional da saúde não deve contra-indicar essas dietas, se a paciente deseja seguí-la. 


\section{REFERÊNCIAS:}

1. Sebastiani, Giorgia et al. The Effects of Vegetarian and Vegan Diet during Pregnancy on the Health of Mothers and Offspring. Nutrients [Internet]. 2019 [cited 2019 Nov 10]; DOI https://doi.org/10.3390/nu11030557. Available from: https://www.mdpi.com/2072$6643 / 11 / 3 / 557 / \mathrm{htm}$

2. Slywitch Eric, compiler. Guia Alimentar de Dietas Vegetarianas para Adultos [bibliography on the Internet]. [place unknown: publisher unknown]; 2012 [cited 2019 Nov 10]. Available from: https://www.svb.org.br/livros/guia-alimentar.pdf

3. Couceiro Patrícia, et al. Padrão alimentar da dieta vegetariana. Einstein [Internet]. 2008 [cited 2019 Nov 10]; Available from: http://www.cookie.com.br/site/wpcontent/uploads/2014/11/padrao_alimentar_da_dieta_vegetariana.pdf

4. Adaikalakoteswari Antonysuni, et al. Low Maternal Vitamin B12 Status Is Associated with Lower Cord Blood HDL Cholesterol in White Caucasians Living in the UK. Nutrients [Internet]. 2015 Apr 02 [cited 2019 Nov 5];7:2401-2414. DOI http://dx.doi.org/10.3390/nu7042401. Available from: https://www.mdpi.com/2072-6643/7/4/2401

5. Deficiência de vitamina A: Departamento Científico De Nutrologia Da Sociedade Brasileira De Pediatria [Internet]. [place unknown]; 2007 Fevereiro. Sociedade Brasileira de Pediatria; [cited 2019 Nov 6]; Available from: https://www.sbp.com.br/fileadmin/user upload/2015/02/doc deficiencia vitamina A.pd

6. Paniz Clovis, et al. Fisiopatologia da deficiência de vitamina B12 e seu diagnóstico laboratorial. Bras Patol Med Lab [Internet]. 2005 Outubro [cited 2019 Nov 6];41:323-34. DOI http://dx.doi.org/10.1590/S1676-24442005000500007. Available from: http://www.scielo.br/pdf/jbpml/v41n5/a07v41n5.pdf

7. Pinheiro Tânia Marisa Macedo. A Importância Clínica da Vitamina D [Monografia on the Internet]. [place unknown]: Universidade Fernando Pessoa Faculdade de Ciências da Saúde;2015. Uniersidade fernando Pesoa; [cited 2019 Nov 6]; Available from: https://bdigital.ufp.pt/bitstream/10284/5301/1/PPG_27959.pdf

8. Colli Célia. Biodisponibilidade de nutrientes. Rev. Bras. Cienc. Farm [Internet]. 2005 Março [cited 2019 Nov 5];41:120. DOI http://dx.doi.org/10.1590/S1516-93322005000100017. Available from:_http://www.scielo.br/scielo.php?script=sci_arttext\&pid=S151693322005000100017\&lng=pt\&nrm=iso\&tlng=pt

9. Arioli Edson L., Corrêa Pedro Henrique S. Hipocalcemia. Arq Bras Endocrinal Metab [Internet]. 1999 Dec 06 [cited 2019 Nov 6]; 41 Available from: http://www.scielo.br/pdf/\%0D/abem/v43n6//11734.pdf

10. Yang Jiaomei, et al. Dietary intakes and dietary patterns among pregnant women in Northwest China. Public Health Nutrition [Internet]. 2016 Aug 30 [cited 2019 Nov 5];20:282-293. DOI http://dx.doi.org/10.1017/s1368980016002159. Available from: https://www.cambridge.org/core/journals/public-health-nutrition/article/dietary-intakes-anddietary-patterns-among-pregnant-women-in-northwestchina/339BB3F814A892B08496A19E889B405A

11. Pereira Giselle A. P, Genaro Patrícia S, Pinheiro Marcelo m, Martini Lígia A, Szejnfeld Vera L. Cálcio dietético - estratégias para otimizar o consumo. Revista Brasileira de Reumatologia. 2009 Jan $11 ;: 164-180$ 
12. Mafra Denise, Cozzolino Sílvia Maria Franciscato. Importância do zinco na nutrição humana. Rev. Nutr [Internet]. 2004 Março [cited 2019 Nov 5];17:79-87. DOI http://dx.doi.org/10.1590/S1415-52732004000100009. Available from:

http://www.scielo.br/scielo.php?script=sci arttext\&pid=S1415$\underline{52732004000100009 \& \operatorname{lng}=\mathrm{pt} \& \operatorname{tlng}=\mathrm{pt}}$

13. Carly Visentin, et al. Low Serum Vitamin B-12 Concentrations Are Prevalent in a Cohort of Pregnant Canadian Women. The Journal Of Nutrition [Internet]. 2016 Apr 13 [cited 2019 Nov 5];146:1035-1042. DOI http://dx.doi.org/10.3945/jn.115.226845. Available from:

https://academic.oup.com/jn/article/146/5/1035/4653026

14. Carmichael Suzan L, et al. Nutritional Factors and Hypospadias Risks. Paediatric And Perinatal Epidemiology [Internet]. 2012 May 17 [cited 2019 Nov 5];26:353-360. DOI http://dx.doi.org/10.1111/j.1365-3016.2012.01272.x. Available from: https://stacks.cdc.gov/view/cdc/33385

15. Henjum Sigrun, et al. Suboptimal Iodine Status and Low Iodine Knowledge in Young Norwegian Women. Nutrients [Internet]. 2018 Jul 21 [cited 2019 Nov 5];10:941-952. DOI http://dx.doi.org/10.3390/nu10070941. Available from:_https://www.mdpi.com/2072$6643 / 10 / 7 / 941$

16. Simões-Wust Ana Paula, et al. Organic food consumption during pregnancy is associated with different consumer profiles, food patterns and intake: the KOALA Birth Cohort Study. Public Health Nutrition [Internet]. 2017 May 31 [cited 2019 Nov 5];20:2134-2144. DOI http://dx.doi.org/10.1017/s1368980017000842. Available from: https://www.cambridge.org/core/journals/public-health-nutrition/article/organic-foodconsumption-during-pregnancy-is-associated-with-different-consumer-profiles-food-patternsand-intake-the-koala-birth-cohort-study/4C95185C5CC57230F8263B399CE5A22C 